\title{
Nickel: Humoral and periodontal changes in orthodontic patients
}

\author{
Leandro Silva Marques ${ }^{1}$, Camila Alessandra Pazzini², Mariele Cristina Garcia Pantuzo³
}

Introduction: Although several studies have discussed nickel influence on the development of immunological reactions in orthodontic patients, it is noticed that the evidence towards the appliances, as well as towards the possible consequences of this material on the oral and general health of the individual are still inconsistent.

Objective: The aim of this article is to present the current stage of knowledge on this issue, highlighting the most recent findings considering the periodontal and humoral aspects of allergic subjects.

Keywords: Nickel. Allergy. Orthodontics.

\section{INTRODUCTION}

Uncover the mechanisms associated with nickel allergy in orthodontic patients means a huge challenge for orthodontists and health researches. Clinical changes like gingival hyperplasia, chapped lips, burning mouth sensation, a metallic taste, angular cheilitis and periodontitis have been associated with the release of nickel from orthodontic appliances. ${ }^{1-8}$ However, critical literature reveals that the most part of evidences provided by researches are little consistent. Part of this issue occurs due to methodological limitations (design, sample size and nature, type of evaluation), leading to conflicting results, affecting the clinical decisions. In addition, there are still unanswered questions, such as:

- What are the implications for clinical and biological nickel allergy?

\footnotetext{
${ }^{1} \mathrm{PhD}$ in Orthodontics, Federal University of Rio de Janeiro (UFRJ).

${ }^{2} \mathrm{PhD}$ student in Pediatric Dentistry, Federal University of Minas Gerais (UFMG).

${ }^{3} \mathrm{PhD}$ in Health Sciences, Federal University of Minas Gerais (UFMG).

Contact address: Leandro Silva Marques

R. Arraial dos Forros, 222 - CEP: 39.100-000 - Diamantina/MG - Brazil

E-mail: lsmarques.prof@gmail.com
}

\footnotetext{
How to cite this article: Marques LS, Pazzini CA, Pantuzo MCG. Nickel: Humoral and periodontal changes in orthodontic patients. Dental Press J Orthod. 2012 MarApr;17(2):15-7.

Submitted: February 02, 2012 - Revised and accepted: March 20, 2012

» The authors report no commercial, proprietary, or financial interest in the products or companies described in this article.

» Patients displayed in this article previously approved the use of their facial and intraoral photographs.
} 
- Are the effects associated with the accumulation of nickel along the orthodontic treatment or with local nickel release?

- Are the reactions mediated by a systemic immune response and/or change of local inflammatory response in the periodontium?

- What is the best way for a clinical orthodontist to deal with a nickel allergic patient?

\section{WHAT IS NEW?}

Recently, prospective studies as well as systematic reviews and meta-analysis, provided important informations for better comprehension of periodontal aspects and humoral characteristics of nickel allergic orthodontic patients. ${ }^{9-13}$

Periodontal conditions were worst in nickel allergic individuals when compared to the non-allergic throughout treatment. ${ }^{9}$ The authors made a longitudinal comparison on the clinical condition of these individuals by means of Löe index for 12 months (one evaluation at every 3 months). A blind evaluation was performed by one single examiner, followed by prophylaxis and hygiene instructions. Significant differences were found between groups in moments $\mathrm{T}_{3}$ and $\mathrm{T}_{4}$ for gingival index, in which allergic individuals presented higher means than the non-allergic ones (hyperplasia, color change and bleeding). Such results suggest nickel cumulative effects along orthodontics treatment, associated with clinically significant periodontal changes.

The authors from the previously mentioned paper also verified the humoral aspects of nickel allergic orthodontic patients and verified a correlation between blood components and possible periodontal changes. Nickel allergy was diagnosed using the patch test, periodontal condition by Löe index and humoral characteristics by means of a complete hemogram, including the measurement of blood nickel and IgE rate. Stool tests were carried out to control parasitic infections. Significant changes were observed between groups considering the granulocytes rate and absence of correlation between blood nickel correlation and IgE rate. Nevertheless, there was positive correlation between gingival index and amount of granulocytes. It can be concluded that there are significant differences considering humoral and periodontal aspects of nickel allergic and nonallergic patients. ${ }^{12}$
Nickel-free brackets have acquired popularity as an adequate alternative for orthodontic allergic patients. This fact has been corroborated by two recent studies: The first, a systematic review developed by Pazzini et al, ${ }^{10,11}$ points out evidences pro-use of nickel free brackets (maximum $2 \% \mathrm{Ni}$ ), although it also highlights the limitation of studies included in the review and the necessity of more consistent evidences. The second study compared longitudinally the periodontal condition of individual treated with traditional and nickel-free brackets. The periodontal condition (gingival hyperplasia, color change and bleeding) was evaluated before beginning treatment $\left(\mathrm{T}_{0}\right)$ and regularly for 12 months (one evaluation at every 3 months $-\mathrm{T}_{1}, \mathrm{~T}_{2}, \mathrm{~T}_{3}$ and $\mathrm{T}_{4}$ ) using Löe index. Blind evaluations were performed for a single calibrated examiner, followed by prophylaxis and hygiene instruction. The periodontal condition for the groups did not differ during the initial 9 months of orthodontic treatment, however, significant changes were found in $\mathrm{T}_{3}$ and $\mathrm{T}_{4}$. Nickel allergic individuals treated with nickel-free brackets showed better periodontal health than individuals treated with conventional brackets. ${ }^{10}$ Figures 1, 2 and 3 illustrate a clinical case whose patient presented nickel allergy and had a significant improvement of periodontal condition after replacing a conventional appliance for a nickel-free one.

Another systematic review on nickel hypersensitivity prevalence in orthodontic patients concluded that orthodontic treatment is not associated with the increase of nickel hypersensitivity prevalence, unless the patient had wore skin piercing. ${ }^{13}$

\section{CLINICAL IMPLICATIONS}

Nickel can promote periodontal changes in allergic patients. This issue becomes critical mainly when we consider the actual increase of demand for orthodontic treatment for adult patients. Such patients, usually, already have had some degree of periodontal commitment. This way, nickel may show itself an aggravating factor. The clinical signs and observed symptoms include oral edema, gingival hyperplasia, perioral stomatitis and gingivitis. No studies were found pointing out how long after bracket removal the reestablishment of normal patterns of the periodontium occurs. 


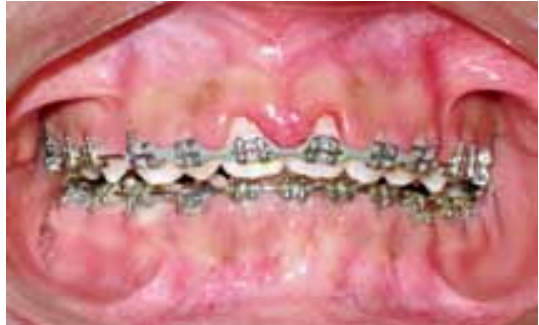

Figure 1 - Clinical condition of allergic patient after six months of treatment.

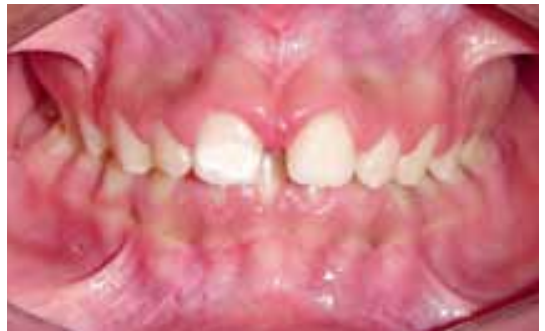

Figure 2 - Clinical condition of patient 1 month after stopping treatment.

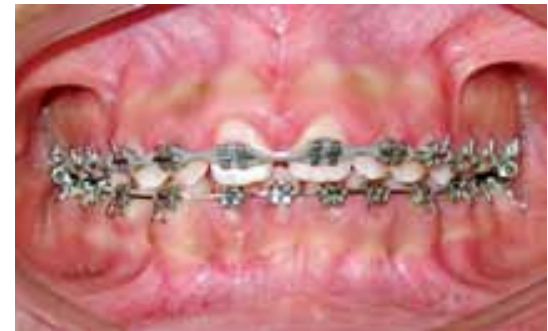

Figure 3 - Clinical condition of the patient three months after reassembly with nickel free bracket.
The potential of orthodontic metals causing allergic reactions is related to the pattern and manner of corrosion, with subsequent release of metal ions, which depends of metal composition, temperature, $\mathrm{pH}$ of the environment, welding presence, wire tension, among others factors. ${ }^{1-4}$

\section{CLINICAL PRACTICE}

It is important to ask during anamnesis about previous nickel sensibility. In allergic patients, the professional must opt for biocompatible materials, thus avoiding welded materials. The use of ceramic, titanium and nickel-free brackets is indicated besides coating the surface of orthodontic accessories with titanium nitride because this nitride is capable to reduce the nickel proportion. Furthermore, it is important to demand special attention of the patient to oral hygiene to minimize metal corrosion.

Further studies should include chromium and cobalt rates, which are substances also present in orthodontic materials and may be overestimating (bias) the effects of nickel. In addition, studies with molecular approach may offer even more solid answers about the actual mechanisms associated to nickel allergy in orthodontic patients.

\section{REFERENCES}

1. Barrett RD, Bishara SE, Quinn JK. Biodegradation of orthodontic appliances. Part I. Biodegradation of nickel and chromium in vitro. Am J Orthod Dentofacial Orthop. 1993;103(1):8-14.

2. Bishara SE, Barrett RD, Selim MI. Biodegradation of orthodontic appliances. Part II. Changes in the blood level of nickel. Am J Orthod Dentofacial Orthop. 1993;103(1):115-9.

3. Fors R, Persson M. Nickel in dental plaque and saliva in patients with and without orthodontic appliances. Eur J Orthod. 2006;28(3):292-7.

4. Levrini L, Lusvardi G, Gentile D. Nickel ions release in patients with fixed orthodontic appliances. Minerva Stomatol. 2006;55(3):115-21.

5. Minang JT, Areström I, Zuber B, Jönsson G, Troye-Blomberg M, Ahlborg N. Nickelinduced IL-10 down-regulates Th1- but not Th2-type cytokine responses to the contact allergen nickel. Clin Exp Immunol. 2006;143(3):494-502.

6. Marigo M, Nouer DF, Genelhu MC, Malaquias LC, Pizziolo VR, Costa AS, et al. Evaluation of immunologic profile in patients with nickel sensitivity due to use of fixed orthodontic appliances. Am J Orthod Dentofacial Orthop. 2003;124(1):46-52.

7. Kao CT, Ding SJ, Min Y, Hsu TC, Chou MY, Huang TH. The cytotoxicity of orthodontic metal bracket immersion media. Eur J Orthod. 2007;29(2):198-203.
8. Fischer LA, Menné T, Johansen JD. Dose per unit area-a study of elicitation of nickel allergy. Contact Dermatitis. 2007;56(5):255-61.

9. Pazzini CA, Oliveira Júnior G, Marques LS, Pereira CV, Pereira LJ. Prevalence of nickel allergy and longitudinal evaluation of periodontal abnormalities in orthodontic allergic patients. Angle Orthod. 2009;79(5):922-7.

10. Pazzini CA, Marques LS, Ramos-Jorge ML, Oliveira Júnior G, Pereira LJ, Paiva SM. Longitudinal assessment of periodontal status in patients with nickel allergy treated with conventional and nickel-free braces. Angle Orthod. 2011 Nov 1. [Epub ahead of print].

11. Pazzini CA, Marques LS, Pereira LJ, Corrêa-Faria P, Paiva SM. Allergic reactions and nickel-free braces: a systematic review. Braz Oral Res. 2011;25(1):85-90.

12. Pazzini CA, Pereira LJ, Carlos RG, de Melo GE, Zampini MA, Marques LS. Nickel: periodontal status and blood parameters in allergic orthodontic patients. Am J Orthod Dentofacial Orthop. 2011;139(1):55-9.

13. Kolokitha OE, Kaklamanos EG, Papadopoulos MA. Prevalence of nickel hypersensitivity in orthodontic patients: a meta-analysis. Am J Orthod Dentofacial Orthop. 2008;134(6):722-34 